\title{
Alterações de isoenzimas peroxidases em plantas de feijoeiro tratadas com biocontrolador do crestamento bacteriano comum
}

\author{
Cheila C. Sbalcheiro ${ }^{1}$, Norimar D. Denardin ${ }^{1}$ \& Sandra P. Brammer ${ }^{2}$ \\ ${ }^{1}$ Universidade de Passo Fundo, Departamento de Fitopatologia; ${ }^{2}$ Embrapa Trigo, 99001-970, Passo Fundo, RS, Brasil \\ Autor para correspondência: Norimar D’Ávila Denardin, e-mail: norimar@upf.br
}

\section{RESUMO}

A cultura do feijoeiro, no Brasil, apresenta constantes danos associados à ocorrência do crestamento bacteriano comum, incitado pela bactéria Xanthomonas axonopodis pv. phaseoli. O objetivo deste trabalho foi avaliar alterações nas isoenzimas peroxidases em plantas de feijoeiro em resposta ao tratamento com biocontrolador do crestamento bacteriano comum. Realizaram-se três experimentos: dois experimentos microbiolizando as sementes com o biocontrolador, avaliando-se as isoenzimas na fase de plântula e na fase de planta adulta e outro experimento aplicando o biocontrolador por aspersão da parte aérea da planta. Para a realização dos experimentos utilizaram-se sementes naturalmente infestadas/infectadas e/ou que sofreram inoculação artificial com o patógeno. Nas análises isoenzimáticas foram detectados 15 padrões de bandas em plântulas e 12 padrões de bandas em planta adulta, tanto nos tratamentos de sementes pela microbiolização com biocontrolador como também nos tratamentos em que a aplicação foi por aspersão da parte aérea com o biocontrolador. Foram observadas diferenças quantitativas (presença e ausência de bandas) quando os tratamentos e os dias após a semeadura foram comparados. Constatou-se o aparecimento de isoperoxidases na região catódica apenas para aqueles tratamentos que receberam o biocontrolador. O microrganismo utilizado como um agente de biocontrole foi efetivo no controle do crestamento bacteriano comum do feijoeiro mostrando ser efetivo na indução de enzimas relacionadas às defesas da planta tanto na aplicação via semente como em aplicação por aspersão na planta.

Palavras-chave: Phaseolus vulgaris, Xanthomonas.

\begin{abstract}
Changes in peroxidase isoenzyme in bean plants treated with a biocontroller of common bacterial blight

Bean crops in Brazil frequently show damages associated with the occurrence of common bacterial blight, incited by Xanthomonas axonopodis pv. phaseoli bacteria. The objective of this study was to evaluate the changes in peroxidase isoenzyme in bean leaves in response to treatment with a biocontroller of common bacterial blight. Three experiments were carried out: two of microbiolization of seed with biocontroller and evaluations at seedling and adult plant stages, and another experiment spraying above-ground parts of plant with the biocontroller. Fifteen band patterns at seedling and twelve patterns at different cycle dates of the crop were detected, both in seeds and above-ground treatments. Quantitative differences were observed (presence and absence of bands) when the treatments and the days after sowing were compared. The presence of isoperoxidases in the cathodic region was seen in the treatments using biocontroller. This organism, used as a method of plant protection against plant pathogens, was shown to be effective after application on plants or seeds, under conditions of common bacterial blight disease.
\end{abstract}

Keywords: Phaseolus vulgaris, Xanthomonas.

\section{INTRODUÇÃO}

O crestamento bacteriano comum do feijoeiro (CBCF), causado pela bactéria Xanthomonas axonopodis pv. phaseoli (Smith, 1897) Vauterin, Hoste, Kerters \& Swinger (1995), é uma doença de difícil controle. A semente é o meio de disseminação e sobrevivência do

Parte da Dissertação de Mestrado do primeiro autor. Universidade de Passo Fundo. Passo Fundo RS. 2006. patógeno mais eficiente. Em condições favoráveis, bastam $0,5 \%$ de sementes infectadas, para produzir uma epidemia no campo (Valarini, 1995), além de aumentar o potencial de inóculo a cada ciclo da cultura (Halfeld-Vieira \& Sousa, 2000). Novas estratégias de controle de plantas estão sendo estudadas, entre elas, biocontrole e indução de resistência através da aplicação de microrganismos não patogênicos .

De acordo com Burdon \& Marshall (1983), em casos de estresses bióticos e abióticos, os estudos isoenzimáticos podem facilitar o entendimento das mudanças metabólicas e mecanismos de defesa desencadeados pelas plantas. $\mathrm{O}$ 
estudo de isoenzimas através de eletroforese é uma técnica bioquímica de custo relativamente baixo e de ótimos resultados, amplamente utilizada em estudos de indução de resistência em plantas, pois as isoenzimas estão diretamente relacionadas com esse mecanismo, em resposta à infecção por patógenos ou agentes de indução. Outro fator de relevância é que as isoenzimas apresentam polimorfismos mais próximos da expressão fenotípica final e são produtos intermediários da expressão de genes (Torggler et al., 1995; Brammer et al., 2002).

Algumas enzimas, como as peroxidases, são capazes de catalisar a transferência do hidrogênio de um doador para $\mathrm{H}_{2} \mathrm{O}_{2}$. Essas enzimas são amplamente distribuídas em todas as plantas e apresentam múltiplas isoformas, as quais estão envolvidas em diversas reações celulares, como a oxidação de compostos fenólicos, oxidação do ácido indol-3-acético, ligações de polissacarídeos, ligações com monômeros, lignificação, cicatrização de ferimentos e o alongamento de células. As peroxidases têm papel fundamental no crescimento e desenvolvimento das plantas, além de estarem fortemente relacionadas com mecanismos de defesa em relação à patógenos e/ou a vários estresses abióticos (Lee et al., 2001; Hsu \& Kao, 2003) e constituem proteção antioxidativa (Rossi et al., 1997). Este largo espectro de funções dessas enzimas é compatível com a presença das várias isoformas, sugerindo que diferentes isoenzimas de peroxidases possivelmente estão envolvidas em processos distintos nas plantas (Caruso et al., 2001).

Gaspar et al. (1986), estudando a atividade das peroxidases durante o crescimento e desenvolvimento das plantas, relacionaram alterações na atividade destas enzimas com mudanças morfogenéticas em resposta ao estresse físico, químico e biológico. Além disso, quando afetada por estresses bióticos, como a infecção por patógenos, a planta aumenta a quantidade de peroxidases produzidas e também a atividade enzimática, estando estas, portanto, relacionadas à proteção celular. Dessa forma, as peroxidases podem ser tomadas como marcadores bioquímicos de estresse resultante de fatores bióticos e abióticos, pelo fato de na maioria das vezes, serem as primeiras enzimas a terem sua atividade alterada, quando a planta é submetida a qualquer condição de estresse (Siegel, 1993). O objetivo do presente trabalho foi avaliar as alterações de isoenzimas peroxidases em plantas de feijoeiro (Phaseolus vulgaris L.) em resposta ao tratamento das sementes e da parte aérea da planta com um isolado de Bacillus sp. em uma formulação a base de polímeros como biocontrolador para o crestamento bacteriano comum, incitado pela bactéria Xanthomonas axonopodis pv. phaseoli.

\section{MATERIAL E MÉTODOS}

O presente trabalho foi conduzido no Laboratório de Fitobacteriologia e casa-de-vegetação da Faculdade de Agronomia e Medicina Veterinária da Universidade de Passo Fundo e no Laboratório de Biotecnologia da Embrapa
Trigo, RS, em outubro de 2004. Foram utilizadas sementes da cultivar BRS Valente da safra 2003/2004, suscetível ao crestamento bacteriano comum (CBCF), oriundas de lavouras de produção de sementes da Região Norte do Estado do Rio Grande do Sul. Esta cultivar está entre as cultivares de feijão preto, registradas e indicadas para o cultivo no Rio Grande do Sul (Comissão..., 2003).

\section{Detecção e quantificação de Xap nas sementes}

A deteç̧ão e quantificação de Xanthomonas axonopodis pv. phaseoli (Xap) nas sementes foi realizada segundo metodologia desenvolvida por (Agostini 2004). As sementes foram desinfestadas superficialmente pela imersão em álcool $70^{\circ} \mathrm{GL}$, por dois min, e em solução de hipoclorito de sódio a $1 \%$, por dois min, e depois, lavadas cinco vezes com água destilada e esterilizada. A extração e a detecção de Xap foi realizada em quatro subamostras de 250 sementes (equivalente a $59 \mathrm{~g}$ sementes em cada subamostra), as quais foram imersas em $500 \mathrm{~mL}$ de solução fisiológica $(0,85 \%$ de $\mathrm{NaCl}$ ) esterilizada, sendo colocadas a seguir sob agitação orbital a $120 \mathrm{rpm}$, durante $12 \mathrm{~h}$ a temperatura de $4^{\circ} \mathrm{C}$. Após a incubação, as suspensões obtidas foram centrifugadas a $3.000 \mathrm{~g}$, por $30 \mathrm{~min}$ e a $4^{\circ} \mathrm{C}$. A seguir, descartou-se o sobrenadante e o 'pellet' foi ressuspendido em $3 \mathrm{~mL}$ de solução fisiológica (Agostini, 2004). A quantificação de Xap foi realizada pela técnica de diluições seriadas, sendo realizadas três diluições, seguidas pelo semeio de alíquota de $200 \mu \mathrm{L}$ de cada diluição em meio 523 (Kado \& Hesket, 1970), espalhando-se na superfície do meio de cultura com auxílio da alça de Drigalsky. A incubação foi em estufa bacteriológica a $28 \pm 1^{\circ} \mathrm{C}$, durante $48 \mathrm{~h}$. Posteriormente, procedeu-se a quantificação das unidades formadoras de colônias (UFC $\mathrm{mL}^{-1}$ ). A quantificação das UFC foi realizada a partir do cálculo: fator de diluição $x$ volume da alíquota (mL) x número de UFC. O resultado obtido através do cálculo foi transformado para a quantidade de gramas de semente utilizada em cada amostra.

\section{Inoculação artificial das sementes de feijoeiro com Xap}

A inoculação artificial das sementes com Xap foi realizada com o isolado 1190-95 de Xanthomonas axonopodis pv. phaseoli, proveniente da coleção de fitobactérias do Instituto Biológico, Estação Experimental de Campinas, SP, como forma de garantir a presença do patógeno nas sementes. Para o preparo do inóculo, colônias puras de Xap foram cultivadas em meio de cultura 523 por $24 \mathrm{~h}$, sendo após o crescimento, ressuspendidas em $10 \mathrm{~mL}$ de solução fisiológica. Dessa suspensão, retirou-se $3 \mathrm{~mL}$, os quais foram adicionados a $50 \mathrm{~mL}$ de meio de cultura líquido 523 , permanecendo sob agitação orbital a $28 \pm 2^{\circ} \mathrm{C}$, a 120 rpm. Após $24 \mathrm{~h}$ de incubação, procederam-se às diluições sucessivas e a semeadura em meio de cultura 523, para determinação da concentração de células. Posteriormente foi realizada a inoculação artificial das sementes com Xap. Para tanto, foram adicionados $3,5 \mathrm{~mL}$ dessa cultura sobre $500 \mathrm{~g}$ de sementes, as quais foram acondicionadas em 
embalagens plásticas, com capacidade de $2 \mathrm{~L}$, e agitandose manual e suavemente por $10 \mathrm{~min}$. As sementes foram mantidas em repouso por $24 \mathrm{~h}$ em ambiente asséptico para a secagem e aderência do inóculo. Após esse período avaliaram-se as UFC por sementes com o intuito de verificar o nível de infestação das mesmas após a inoculação com o patógeno.

\section{Preparo do agente de biocontrole}

Para o preparo da formulação, utilizou-se um isolado de Bacillus sp. Esse isolado está sendo determinado por sequênciamento da região $16 \mathrm{SrDNA}$ (dados não publicados). Colônias puras desse isolado bacteriano crescidas em meio de cultura 523, por $24 \mathrm{~h}$, foram ressuspendidas em $3 \mathrm{~mL}$ de solução fisiológica, transferidas para erlenmeyer contendo $50 \mathrm{~mL}$ de meio de cultura líquido 523 , mantida sob agitação orbital por $48 \mathrm{~h} \mathrm{a} 28 \pm 1^{\circ} \mathrm{C}$ e a $120 \mathrm{rpm}$. As UFC de Bacillus sp. presentes no caldo foram avaliadas através do método de diluição seriada semeando-se uma alíquota de $200 \mu \mathrm{L}$ em meio de cultura 523. Após, alíquotas de $5 \mathrm{~mL}$ desse inóculo foram adicionadas a $20 \mathrm{~mL}$ de um suporte à base de polímeros (Denardin \& Freire, 2000), compondo a partir desse momento o biocontrolador, que foi homogeneizado por agitação, procedendo-se, posteriormente, a contagem de UFC.

A escolha da formulação e do microrganismo foi baseada nos resultados obtidos por Agostini (2004), Tedesco (2005) e Sbalcheiro (2006), que evidenciaram redução de 40,50 e $56 \%$, respectivamente, do crestamento bacteriano comum do feijoeiro, durante o ciclo da cultura, através da microbiolização das sementes com o biocontrolador.

\section{Microbiolização das sementes com biocontrolador}

Para a microbiolização das sementes, foram adicionados $3,5 \mathrm{~mL}$ do biocontrolador a $500 \mathrm{~g}$ de sementes, as quais foram acondicionadas em embalagens plásticas com capacidade de 2 L. Para completa cobertura das sementes e distribuição uniforme do biocontrolador, as embalagens foram fechadas, agitadas manual e suavemente por $10 \mathrm{~min}$ e mantidas em ambiente asséptico por $5 \mathrm{~h}$. Após esse período procedeu-se o plantio das sementes em casa de vegetação. A quantificação de Bacillus sp. presentes externamente nas sementes foi realizada após este período pela extração em solução fisiológica e semeadura em meio de cultura 523, conforme citado anteriormente. Foram realizados três experimentos, todos conduzidos em delineamento estatístico inteiramente casualizado.

\section{Experimento I}

Para a condução dos ensaios, as seguintes combinações detratamentos foramestabelecidas:Tratamento 1 ( $\mathrm{T}_{1}$ - controle): sementes com infecção natural de Xap; Tratamento $2\left(\mathrm{~T}_{2}\right)$ : sementes com infecção natural mais inoculação artificial com Xap; Tratamento $3\left(\mathrm{~T}_{3}\right)$ : sementes com infecção natural mais inoculação artificial com Xap e microbiolização com biocontrolador; e Tratamento $4\left(\mathrm{~T}_{4}\right)$ : sementes com infecção natural e microbiolização com biocontrolador.

Cada tratamento constituiu-se de 50 sementes as quais foram semeadas, individualmente, em copos plásticos de $250 \mathrm{~mL}$ contendo mistura de vermiculita, areia e carvão (3:1:1) esterilizada, totalizando 200 vasos. A adubação foi realizada com solução nutritiva de Hoagland \& Arnon (1950) intercalando-se com água destilada e esterilizada. O tecido foliar foi coletado no estádio V2 de desenvolvimento da cultura (Gepts \& Fernández, 1982), cerca de 30 dias após a semeadura, realizando-se três coletas, denominadas de $1^{\mathrm{a}}, 2^{\mathrm{a}}$ e $3^{\mathrm{a}}$ época, com intervalos de cinco dias cada. Cada amostra foi composta de três discos foliares, de diâmetro aproximado de $8,44 \mathrm{~mm}$, de uma mesma planta, coletados ao acaso totalizando 30 discos por tratamento. Cada três discos foi considerado como sendo uma repetição, totalizando dessa forma 10 repetições por tratamento para cada época. As amostras foram mantidas em microtubos de $1,5 \mathrm{~mL}$ a $-4^{\circ} \mathrm{C}$.

\section{Experimento II}

Os mesmos tratamentos do experimento I foram utilizados nesse ensaio. Entretanto, as sementes foram distribuídas em vasos com capacidade para $3 \mathrm{~kg}$ de solo que foi corrigido conforme indicações técnicas para a cultura (Comissão..., 2003), sendo cada parcela constituída por 10 vasos com cinco plantas cada. O tecido foliar foi coletado aos 34, 49, 64 e 79 dias após a semeadura, ou seja, estádio V3 a R6. Cada amostra constituiu-se de três discos foliares oriundos de folíolos do terço médio de cada planta. Foram coletadas três amostras de plantas diferentes totalizando nove discos por tratamento por época. Cada amostra de três discos foi considerado uma repetição. Os discos foliares foram acondicionados em microtubos de $1,5 \mathrm{~mL}$ e mantidos a $-4^{\circ} \mathrm{C}$.

\section{Experimento III}

Sementes de feijoeiro com infecção natural de Xap foram plantadas em vasos com capacidade para $3 \mathrm{~kg}$ de solo que foi corrigido conforme descrito para o experimento II e mantidos em casa de vegetação com condições ideais para o desenvolvimento da doença. Nesse experimento foram utilizados os seguintes tratamentos: $\mathrm{T}_{1}$ : controle - sementes com infecção natural de Xap e aspersão foliar com água; $\mathrm{T}_{2}$ : sementes com infecção natural mais uma aplicação foliar com biocontrolador, aos 35 dias após a semeadura; $\mathrm{T}_{3}$ : sementes com infecção natural mais duas aplicações foliares com biocontrolador, aos 35 e 50 dias após a semeadura; $\mathrm{T}_{4}$ : sementes com infecção natural mais três aplicações foliares com biocontrolador, aos 35, 50 e 65 dias após a semeadura. Para $\mathrm{T}_{2}$ e $\mathrm{T}_{3}$ foi aspergida água deionizada e esterilizada nos dias correspondentes as aplicações com biocontrolador nos demais tratamentos, para simular as mesmas condições de molhamento.

Para aplicação do biocontrolador na parte aérea das plantas, diluiu-se $25 \mathrm{~mL}$ do biocontrolador em $400 \mathrm{~mL}$ de 
água destilada e esterilizada (1:16, v:v). A concentração do Bacillus sp. após a diluição do biocontrolador em água, foi de 2,2 x $10^{7} \mathrm{UFC} \mathrm{mL}^{-1}$. O biocontrolador foi aplicado por aspersão em toda parte aérea das plantas até o ponto de escorrimento, conforme detalhado nos tratamentos. O controle foi aspergido com água destilada e esterilizada. $\mathrm{O}$ tecido foliar de cada tratamento foi coletado momentos antes da aplicação e quatro dias após a aplicação do produto. As amostras foram constituídas e coletadas da mesma forma que no experimento II.

\section{Eletroforese das isoenzimas}

$\mathrm{Na}$ eletroforese das isoenzimas de peroxidase (PO, EC 1.11.1.7) foram utilizados três discos foliares, sendo cada disco considerado uma repetição por amostra, totalizando nove repetições por tratamento. As soluções tampão das amostras, da eletroforese e dos géis foram preparadas segundo Scandalios (1969). As amostras foram aplicadas em géis de poliacrilamida a $6 \%$ e migradas em corrente contínua, posição horizontal e temperatura constante de $4^{\circ} \mathrm{C}$. A distância entre a ponte catódica e anódica foi de $12,0 \mathrm{~cm}$, a intensidade de campo utilizada foi de $10 \mathrm{~V} \mathrm{~cm}^{-1}$ e o processo de migração foi interrompido quando a linha de frente, marcada com azul de bromofenol, atingiu $10,0 \mathrm{~cm}$. A coloração dos géis foi feita com 20 $\mathrm{mL}$ da solução de benzidina $(0,5 \mathrm{~g}$ de benzidina, $9 \mathrm{~mL}$ de ácido acético glacial e $36 \mathrm{~mL}$ de água destilada) e $20 \mathrm{~mL}$ de peróxido de hidrogênio $0,075 \%$, mantidos sob agitação. Após o aparecimento das bandas, o gel foi lavado com água destilada e a seguir adicionaram-se $50 \mathrm{~mL}$ de álcool etílico $50 \%$, por 10 min para interromper a reação de revelação. A seguir, os géis foram mantidos em água destilada e a análise das bandas realizada imediatamente após a coloração.

As análises das isoperoxidases foram baseadas na representação da migração absoluta (MA) e cálculo da migração relativa (MR), conforme Sbalcheiro et al. (2005). Bandas de difícil visualização foram desconsideradas. Para cada MR, foi calculada a freqüência da banda (FB), dividindo-se o número de vezes em que a banda apareceu nas amostras pelo número total de amostras.

\section{RESULTADOS E DISCUSSÃO}

A concentração de Xap encontrada infestando/ infectando naturalmente as sementes de feijoeiro na cultivar BRS Valente foi de $1,5 \times 10^{5} \mathrm{UFC} \mathrm{g}^{-1}$ semente. As sementes inoculadas com a suspensão contendo $1,2 \times 10^{8}$ UFC $\mathrm{mL}^{-1}$ de Xap, apresentaram 1,9 x $10^{5} \mathrm{UFC}_{\text {semente }}{ }^{-1}$ de Xap após a inoculação artificial. A concentração de Bacillus sp. encontrada nas sementes após a microbiolização com o biocontrolador foi de 2,6 x $10^{3}$ UFC semente- . $^{-1}$.

\section{Análise das isoperoxidades}

$\mathrm{Na}$ análise de isoperoxidases, observaram-se diferenças significativas entre os tratamentos e os dias após a semeadura, ocorrendo diferenças quantitativas (presença e ausência de banda). A variabilidade encontrada em certas isoenzimas pode estar relacionada à sobrevivência da planta em diversos ambientes. Desta forma, fatores como nutrição, temperatura, presença de microrganismos não patogênicos na rizosfera e filosfera e infecção por patógenos afetam o metabolismo da planta, influenciando na intensidade da atividade enzimática. Pequenas mudanças nessa atividade podem induzir ao surgimento de formas moleculares múltiplas, por estarem ligadas a ativação de genes (Sbalcheiro et al., 2005).

\section{Experimento I-Aplicação do biocontrolador via semente, com semeio em copos contendo substrato esterilizado}

Foram detectados 15 padrões de bandas, cujas MRs variaram de 0,05 a 0,65 na região anódica. Na região catódica foram observadas bandas com MRs de - 0,14 e 0,16 . A variação qualitativa foi medida pela intensidade da banda, variando entre fraca, média e forte (Figura 1).

As bandas de MRs 0,10 e 0,05 foram encontradas em todas as plantas avaliadas e em todos os tratamentos, apresentando a maior FB e destacando-se das demais pela intensidade forte e média, respectivamente. As bandas de MRs $0,30,0,46,0,53,0,57$ e 0,65 não apareceram nas plantas do $\mathrm{T}_{1}$ (controle), indicando que estas bandas não são expressas nas plantas no estádio V2 de desenvolvimento, com infecção natural do patógeno. Da mesma maneira, a banda de MR 0,20 não apareceu no $\mathrm{T}_{3}$, supondo-se que a expressão desta banda foi suprimida em condições de interação da planta com elevada infecção e presença do biocontrolador, uma vez que ela apareceu nos demais tratamentos. $T_{3}$ foi o único tratamento que apresentou atividade da enzima na região catódica, cujas bandas tiveram MRs de $-0,14$ e $-0,16$, indicando que tais isoformas podem estar associadas diretamente com o desenvolvimento de indução de resistência nas plantas, conferida pelo agente biocontrolador contra infecções de Xap acima de $1,5 \times 10^{5} \mathrm{UFC} \mathrm{g}^{-1}$ semente. Segundo alguns autores, a elevada atividade de isoenzimas de peroxidase está relacionada à resistência das plantas a determinados patógenos e pode ser utilizada como marcador bioquímico de resistência, a exemplo dos binômios alface x Bremia lactucae e melão x Pseudoperonospora cubensis (Reuveni et al., 1992). No T 4 , observou-se a presença da banda de MR 0,53 com elevada atividade na $2^{\mathrm{a}}$ e $3^{\mathrm{a}}$ épocas de coleta. Essa isoforma pode ser resultado da ação do biocontrolador como indutor de resistência, indicando o momento da indução de defesa na planta.

Nandakumar et al. (2001), em estudo sobre o controle de Rhizoctonia solani em arroz com linhagens de Pseudomonas fluorescens observaram, por um período de $96 \mathrm{~h}$ pós-tratamento, que houve aumento na atividade de peroxidases apenas nas plantas que foram tratadas com a bactéria e inoculadas com o patógeno em contraposição às plantas sem tratamento e/ou aquelas tratadas, mas que não foram inoculadas, nas quais não houve alteração das atividades destas enzimas. Os autores também encontraram cinco isoenzimas de peroxidase (PO1-PO5) em plantas de 

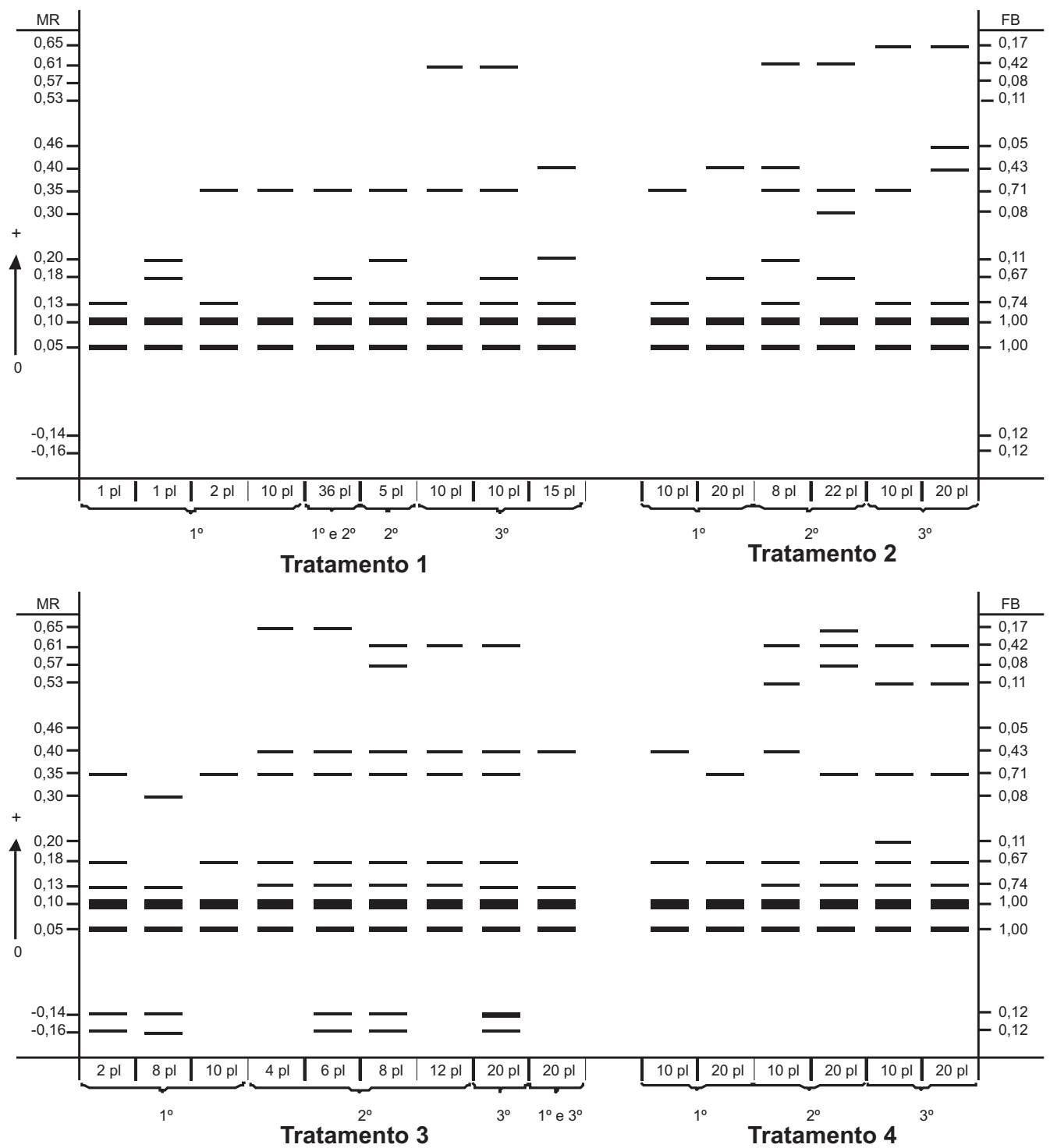

FIGURA 1 - Zimograma representando os 15 padrões de bandas de isoperoxidases em plântulas de feijoeiro, submetidas a microbiolização de sementes, com sua respectiva migração relativa (MR), quantidade de plantas (pl) por época de coleta e freqüência da banda (FB). (A) Tratamento 1 - controle: sementes com infecção natural com Xanthomonas axonopodis pv. phaseoli - Xap; Tratamento 2: sementes com infecção natural mais inoculação artificial com Xap; (B) Tratamento 3: sementes com infecção natural mais inoculação artificial com Xap e microbiolização com biocontrolador; Tratamento 4: sementes com infecção natural mais microbiolização. Intensidade das bandas: fraca —- média —, forte - ; Épocas de coleta: $1^{\circ}$ - 30 dias após a semeadura, $2^{\circ}-35$ dias após a semeadura e $3^{\circ}$ - 40 dias após a semeadura.

arroz tratadas com uma formulação da bactéria, mas apenas três (PO1-PO3) nas plantas não tratadas com a formulação e inoculadas com o patógeno. Os autores concluíram que as linhagens de $P$. fluorescens induziram resistência sistêmica na planta, controlando o patógeno $R$. solani. Dessa forma, a presença da banda de MR 0,53 encontrada no presente trabalho, pode indicar indução de resistência sistêmica, como o observado por esses autores.
A banda de MR 0,30 que apareceu em $\mathrm{T}_{2}$ e $\mathrm{T}_{3}$ do experimento I, em que havia sido feita inoculação artificial comXap, podeindicarqueapresençadeumamaiorquantidade de inóculo, pode desencadear a ativação isoenzimática e gerar isoformas específicas frente à infecção do patógeno. Da mesma maneira, Campos et al. (2004), trabalhando com plantas de feijoeiro tratadas com substâncias indutoras de resistência (fungo indutor Colletotrichum lindemuthianum 
ou ácido salicílico) e desafiadas após três dias com o patótipo virulento, observaram nos dois casos, o aparecimento de uma nova banda com atividade peroxidásica, perto da linha de frente, banda esta não detectada nas plantas sadias ou sem estímulo de indução, nem na cultivar Carioca, considerada suscetível.

Segundo Nandakumar et al. (2001), a indução da produção de enzima nas plantas não tratadas com Pseudomonas foi mais forte apenas no estágio inicial de patogênese, apresentando logo em seguida uma redução, enquanto nas plantas tratadas a atividade da enzima permaneceu intensa mesmo após uma semana da inoculação com o patógeno. De acordo com diversas bibliografias e melhor enfocado por Nandakumar et al. (2001), há um aumento na atividade da enzima, que se mantém por um período relativamente longo, quando da indução de sua produção por uma substância externa.

De modo geral, observou-se menor atividade isoperoxidásica em $\mathrm{T}_{1}, \mathrm{~T}_{2} \mathrm{e}_{3}$, principalmente na primeira época. Em $\mathrm{T}_{3}$ e $\mathrm{T}_{4}$, observou-se a maior atividade desta enzima nas duas últimas épocas de coleta. Esta isoperoxidase pode estar presente em mínimas quantidades na planta, e com o estímulo do biocontrolador e da própria bactéria patogênica, passa a ser sintetizada de novo, conforme comentado por Siegel (1993).

Experimento II - Aplicação do biocontrolador via semente, com semeio em vasos contendo solo

Na avaliação das isoperoxidases, nesse experimento, foram detectados um total 12 padrões de bandas, cujas
MRs variaram de 0,05 a 0,57 na região anódica e na região catódica apresentaram uma banda de $\mathrm{MR}-0,14$. A intensidade fraca das bandas foi a mais freqüente, sendo que as de MRs 0,05 e 0,10 apresentaram intensidade média e forte, respectivamente. A de MR 0,10 apresentou FB de 1,00 e a de MR 0,57 apresentou a menor FB $(0,06)$ (Figura 2). Aos 34 dias após a semeadura as plantas em $\mathrm{T}_{1}$ (controle) apresentaram baixa atividade da isoenzima, podendo indicar que as isoperoxidases relacionadas com a defesa ainda não estavam ativadas neste estádio. Contudo, observou-se um aumento crescente da atividade da enzima ao longo do ciclo da cultura, podendo explicar uma resposta da planta à infecção bacteriana.

Em relação ao $\mathrm{T}_{2}$, detectou-se que aos 34 dias as plantas já apresentavam elevada atividade da enzima, que se manteve durante todo o período avaliado, devido à maior quantidade de inóculo na semente, e a planta iniciar sua reação de defesa diante da presença do patógeno, conforme já relatado por outros autores para outros patossistemas. Em $\mathrm{T}_{4}$, observou-se elevada atividade da enzima, principalmente no último período de avaliação permanecendo elevada durante todo o ciclo avaliado, sugerindo que houve reação da planta contra o patógeno proporcionada pela aplicação do biocontrolador. A maior atividade detectada de isoenzimas de peroxidase com similaridade de padrões de bandas em plantas tratadas e não tratadas com formulações biocontroladoras, sugere que diferenças nas isoformas associadas com a indução de resistência são quantitativas, mas não qualitativas (Nandakumar et al., 2001).

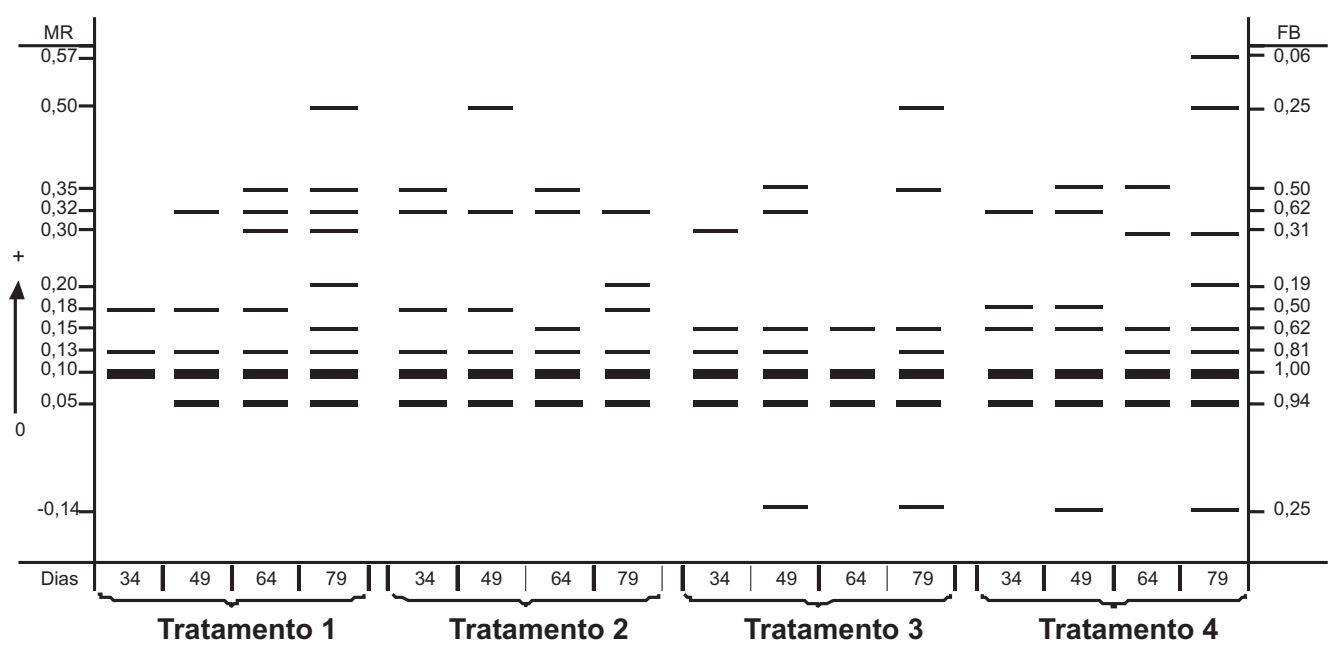

FIGURA 2 - Zimograma representando os 12 padrões de bandas de isoperoxidases em feijoeiro, submetidos à microbiolização das sementes, obtidas aos 34, 49, 64 e 79 dias após a semeadura (DAS) com sua respectiva migração relativa (MR) e freqüência da banda (FB), conforme o tratamento. Tratamento 1 - controle: sementes com infecção natural com Xanthomonas axonopodis pv. phaseoli-Xap; Tratamento 2: sementes com infecção natural e inoculação artificial com Xap; (B) Tratamento 3: sementes com infecção natural, inoculação artificial e microbiolização com biocontrolador; Tratamento 4: sementes com infecção natural e microbiolização com biocontrolador. Intensidade das bandas: fraca - , média $\_$, forte ${ }_{-}$. 


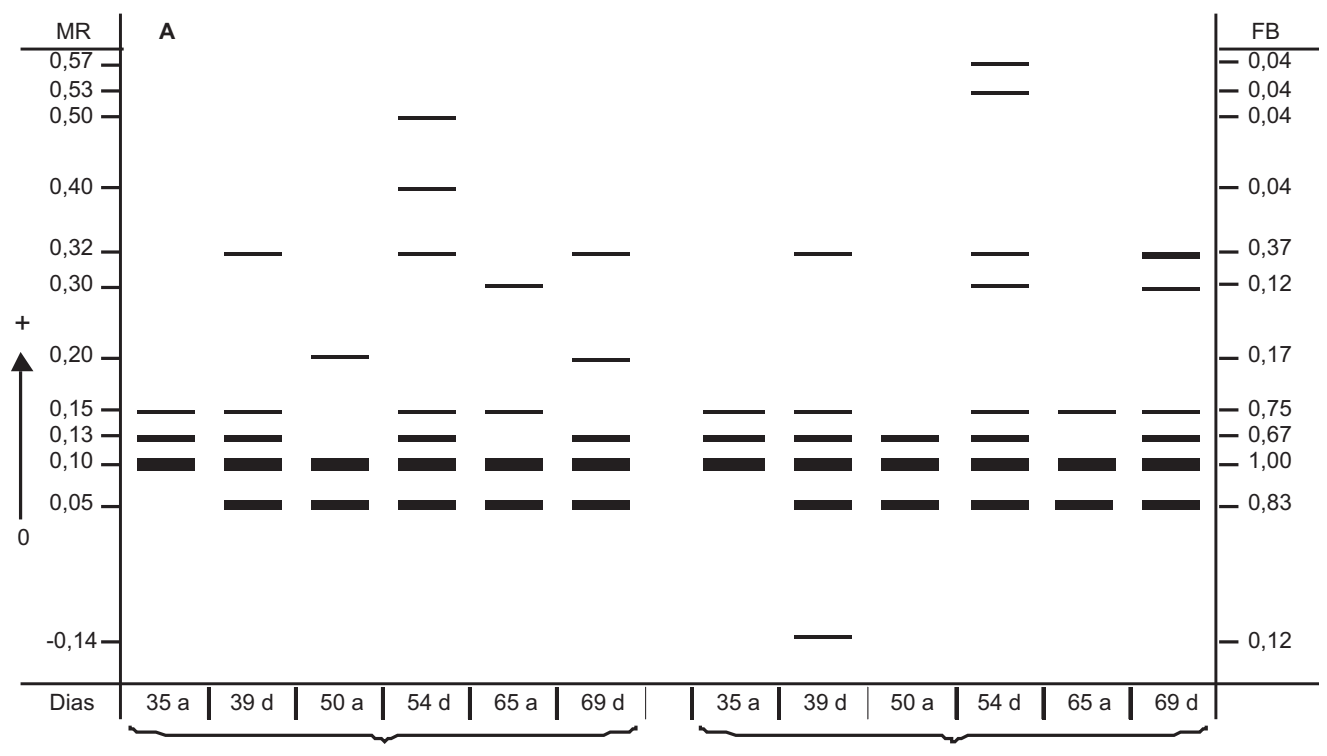

Tratamento 1

Tratamento 2

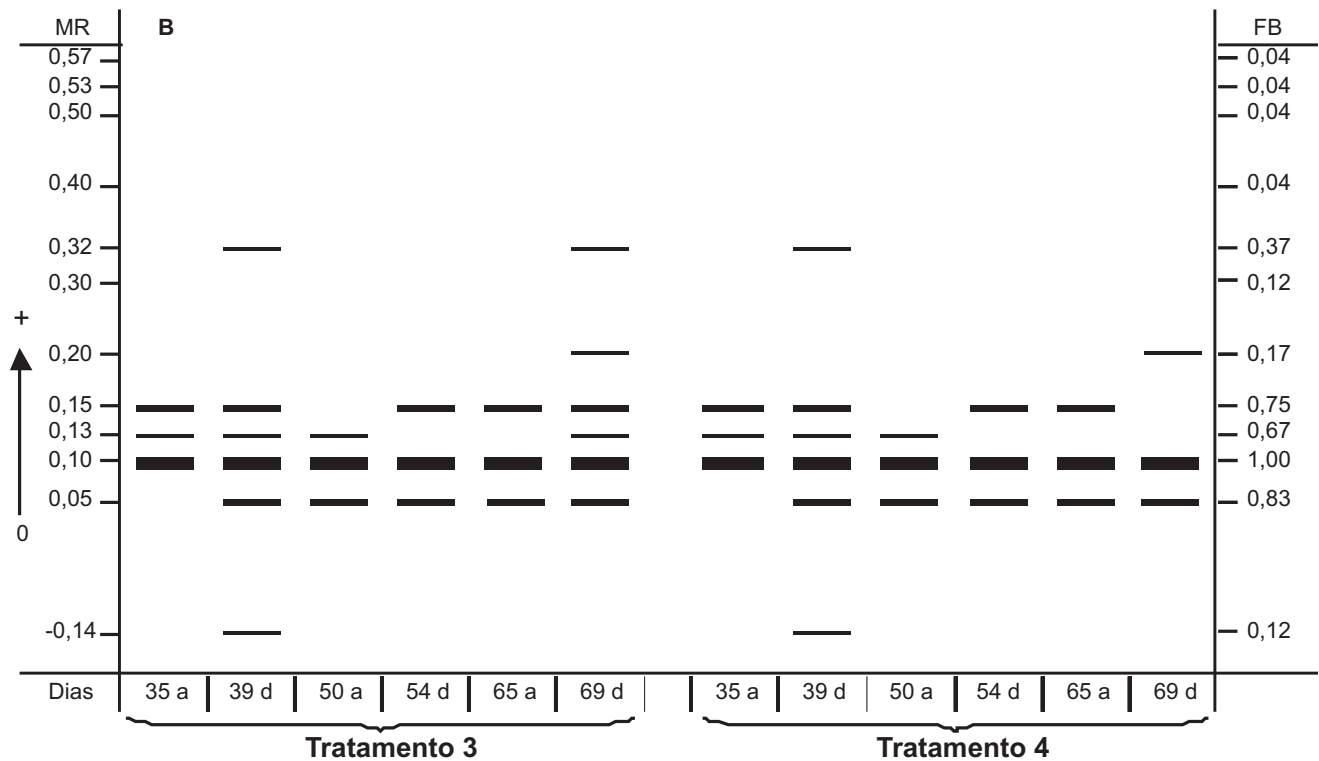

FIGURA 3 - Zimograma representando os 12 padrões de bandas de isoenzimas de peroxidases em feijoeiro, submetidos à aplicação do biocontrolador na parte aérea da planta, com sua respectiva migração relativa (MR) e freqüência da banda (FB), conforme os dias após a semeadura (DAS). (A) Tratamento 1 - controle: sementes com infecção natural com Xanthomonas axonopodis pv. phaseoli-Xap e aspersão foliar com água; Tratamento 2: sementes com infecção natural mais uma aplicação foliar com biocontrolador, 35 DAS; (B) Tratamento 3: sementes com infecção natural mais duas aplicações foliares com biocontrolador, 35 e 50 DAS; Tratamento 4: sementes com infecção natural mais três aplicações foliares com biocontrolador, 35, 50 e 65 DAS. Intensidade de banda: fraca — , média —, forte ; a: antes da aplicação com biocontrolador ou água, d: depois da aplicação com biocontrolador ou água.

A isoforma de MR 0,20 apareceu em $\mathrm{T}_{1}, \mathrm{~T}_{2}$ e $\mathrm{T}_{4}$ somente no final do ciclo avaliado, mas não em $\mathrm{T}_{3}$. Apenas em $\mathrm{T}_{4}$, observou-se a presença da isoforma de MR 0,57 e a banda de MR 0,30 não foi ativada em $\mathrm{T}_{2}$. A banda de MR -0,14 apareceu em $\mathrm{T}_{3}$ e $\mathrm{T}_{4}$, em que as sementes foram microbiolizadas com o biocontrolador, aos 49 e 79 dias após a semeadura, podendo-se inferir que o biocontrolador induziu a ativação desta isoforma independentemente da concentração de Xap presente nas sementes. De acordo com Mozzetti et al. (1995), correlação positiva entre resistência varietal a fungos fitopatogênicos e aumento na atividade de peroxidases, mesmo em plantas ou 
partes de plantas não inoculadas com o patógeno, tem sido amplamente relatada na literatura. Segundo esses mesmos autores, elevados níveis da enzima foram observados em plantas de pimentão imunizadas local ou sistemicamente contra diferentes patógenos, mas que não sofreram inoculação, especialmente folhas de pimentão cuja resistência a Phytophthora capsici foi induzida por elicitores. Entretanto, no estudo realizado por esses autores, observou-se em plantas inoculadas e não tratadas com substâncias indutoras de resistência, maiores taxas de atividade da enzima quanto maior a suscetibilidade da cultivar de pimentão.

\section{Experimento III - Aplicação do biocontrolador por aspersão via foliar}

Observou-se diferenças antes e depois da aplicação do agente indutor (biocontrolador), mas poucas diferenças entre os tratamentos. Foram detectadas no total 12 padrões de bandas, com MRs de 0,05 a 0,57 na região anódica e MR $-0,14$ na região catódica. A banda de MR 0,10 apresentou intensidade forte e a maior FB $(1,00)$. As de MRs $0,50,0,53$ e 0,57 apresentaram a menor FB $(0,04)$ (Figura 3 ).

Todos os tratamentos, inclusive o controle, apresentaram variação nos padrões de banda antes e após a aplicação do biocontrolador ou da água, diferentemente do encontrado por Ye et al. (1990), em que a atividade da peroxidase aumentou rapidamente (6-12 dias) após a inoculação de plantas de fumo com Tobacco mosaic virus TMV para indução de resistência sistêmica, em comparação com a atividade de plantas controle tratadas com água, que permaneceram com o mesmo nível de atividade da enzima.

A banda de MR 0,20 não foi observada em $T_{2}$ e nos demais tratamentos apareceu no final do período avaliado (69 dias após a semeadura). Ainda em $\mathrm{T}_{2}$, as bandas de MRs 0,53 e 0,57 estavam ativas. A banda de MR -0,14, apareceu em $\mathrm{T}_{2}, \mathrm{~T}_{3} \mathrm{e} \mathrm{T}_{4}$, apenas após a primeira aplicação do biocontrolador. Para $\mathrm{T}_{4}$, em que foram feitas três aplicações com o biocontrolador, a atividade da enzima apenas foi aumentada depois da primeira aplicação, indicando não haver necessidade de mais de uma aplicação. Em comparação a $\mathrm{T}_{3}$, em que foram realizadas duas aplicações, a atividade da enzima foi semelhante nos dois casos.

As poucas diferenças observadas entre os tratamentos na aplicação foliar, não observada na aplicação na semente, explica-se pelo fato do agente biocontrolador não possuir adaptabilidade para sobreviver na filosfera. Porém, observa-se que em todos os modos de aplicação do biocontrolador houve desencadeamento de mecanismos de defesa. Entretanto, recomenda-se que sejam conduzidos novos estudos de biocontrole, visando explorar novos aspectos que confirmem as observações encontradas nesse trabalho, assim como estudar o possível envolvimento de substâncias produzidas por esses agentes de biocontrole na indução de resistência e no controle de patógenos na busca de resultados que possibilitem o aumento do uso de produtos de biocontrole contra fitopatógenos.

\section{REFERÊNCIAS BIBLIOGRÁFICAS}

Agostini VA (2004) Detecção e biocontrole de Xanthomonas axonopodis pv. phaseoli var. fuscans (Smith) Dye em sementes de feijoeiro comum (Phaseolus vulgaris L.). Dissertação de Mestrado. Passo Fundo RS. Universidade de Passo Fundo.

Brammer SP, Salazar S, Moraes-Fernandes MIB, Barcellos AL (2002) Identificação de marcadores isoesterásicos associado ao gene Lr24 com resistência à ferrugem da folha em trigo. Passo Fundo RS. Embrapa Trigo. Circular Técnica Online 13.

Burdon JJ, Marshall DR (1983) The use of isozyme research. In: Tanksley SD, Orton TJ (Eds.) Isozymes in Plant Genetics and Breeding: part A. Amsterdam. Elsevier Science. pp. 401-412.

Campos AD, Ferreira AG, Hampe MMV, Antunes IF, Brancão N, Silveira EP, Osório VA, Augustin E (2004) Atividade de peroxidase e polifenoloxidase na resistência do feijão à antracnose. Pesquisa Agropecuária Brasileira 39:637-643.

Caruso C, Chilosi G, Leonardi L, Bertini L, Magro P, Buonocore V, Caporale C (2001) A basic peroxidase from wheat kernel with antifungal activity. Phytochemistry 58:743-750.

Comissão Estadual de Pesquisa de Feijão - CEPEF (2003). Indicações Técnicas para a Cultura do Feijão no Rio Grande do Sul 2003/04. Passo Fundo RS. Universidade de Passo Fundo.

Denardin ND, Freire JRJ (2000) Assessment of polymers for the formulation of legume inoculantes. World Journal of Microbiology \& Biotechnology 16:215-217.

Gaspar T, Penel C, Castillo FJ, Greppin H (1986) A two-step control of basic and acidic peroxidases and its significance for growth and development. Physiologia Plantarum 64:418-423.

Gepts P, Fernández F (1982) Etapas de desarrollo de la planta de frijol comum (Phaseolus vulgaris L.). Cali Colombia. CIAT.

Halfeld-Vieira BA, Sousa RM de (2000) Virulência de isolados de Xanthomonas axonopodis pv. phaseoli e sua variante fuscans. Ciência Agrotécnica 24:94-102.

Hoagland R, Arnon I (1950) The water culture method for growing plants without soil. Circular of the California Agricultural Experiment Station 347:1-32.

Hsu SY, Kao CH (2003) Differential effect of sorbitol and polyethylene glycol on antioxidant enzymes in rice leaves. Plant Growth Regulation 39:83-89.

Kado CI, Heskett MG (1970) Selective media for isolation of Agrobacterium, Corynebacterium, Erwinia, Pseudomonas, and Xanthomonas. Phytopathology 60:969-976.

Lee SH, Kim ES, Lee MY (2001) Purification and characterization of a cationic isoperoxidase from scented-geranium. Phytochemistry 58:859-864.

Mozzetti C, Ferraris L, Tamietti G, Matta A (1995) Variation in enzyme activities in leaves and cell suspensions as markers of incompatibility in different Phytophthora-pepper interactions. Physiological and Molecular Plant Pathology 46:95-107.

Nandakumar R, Babu S, Viswanathan R, Raguchander T, Samiyappan R (2001) Induction of systemic resistance in rice against sheath blight disease by Pseudomonas fluorescens. Soil Biology \& Biochemistry 33:603-612.

Reuveni R, Shimoni M, Karchi Z, Kuć J (1992) Peroxidase activity 
as a biochemical marker for resistance of muskmelon (Cucumis melo) to Pseudoperonospora cubensis. Phytopathology 82:749753.

Rossi C, Lima GPP, Hakvoort DMR (1997) Atividade de peroxidases (EC 1.11.1.7) e teor de prolina no embrião e cotilédones de feijoeiro Phaseolus vulgaris L. cultivado em condições de salinidade. Scientia Agricola 54:123-127.

Sbalcheiro CC, Brammer SP, Barcellos AL (2005) Variabilidade isoesterásica associada a genes de resistência à ferrugem da folha do trigo. Fitopatologia Brasileira 30:267-273.

Sbalcheiro CC (2006) Ação do biocontrolador com atividade de indução de resistência no controle do crestamento bacteriano comum do feijoeiro (Phaseolus vulgaris L.). Dissertação de Mestrado. Passo Fundo RS. Universidade de Passo Fundo.

Scandalios JG (1969) Genetic control of multiple forms of enzymes in plants: a review. Biochemical Genetics 3:37-79.

Siegel BZ (1993) Plant peroxidases - an organismic perspective. Plant Growth Regulation 12:303-312.

Tedesco V (2005) Biocontrole do crestamento bacteriano comum do feijoeiro nos cultivares Valente e Soberano através da microbiolização de sementes com o isolado de Actinomiceto UFV014. Dissertação de Mestrado. Passo Fundo RS. Universidade de Passo Fundo.

Torggler MGF, Contel EPB, Torggler SP (1995) Isoenzimas variabilidade genética em plantas. Ribeirão Preto SP. Sociedade Brasileira de Genética.

Valarini PJ (1995) Detecção do agente causal do crestamento bacteriano comum em sementes de feijão. In: Valarini PJ (Ed.) Patógenos em sementes: deteç̧ão, danos e controle químico. São Paulo SP. Ciba Agro. pp. 53-54.

Valterini L, Hoste B, Kersters K, Swings J (1995) Reclassification of Xanthomonas. Internation Journal of Systematic Bacteriology 45:472-489.

Ye XS, Pan SQ, Kuć J (1990) Activity, isozyme pattern, and cellular localization of peroxidases as related to systemic resistance of tobacco to Blue Mold (Peronospora tabacina) and to Tobacco mosaic virus. Phytopathology 80:1295-1299.

Young JM, Saddler GS, Takikawa Y, De Boer SH, Vauterin L, Gardan L, Gvozdyak RI, Stead DE (1996) Names of plant pathogenic bacteria. Review Plant Pathology 75:721-763. 